\title{
How Do Consumers Consume Fashion Online? A Practice-Theoretical Inquiry
}

\author{
Susanna Salonen ${ }^{1}$, Elina Närvänen ${ }^{1} \&$ Hannu Saarijärvi ${ }^{1}$ \\ ${ }^{1}$ School of Management, University of Tampere, Tampere, Finland \\ Correspondence: Elina Närvänen, School of Management, 33014 University of Tampere, Finland. Tel: \\ 358-40-596-8884. E-mail: elina.narvanen@uta.fi
}

$\begin{array}{ll}\text { Received: February 24, } 2014 & \text { Accepted: March 13, 2014 Online Published: May 21, } 2014 \\ \text { doi:10.5539/ijms.v6n3p87 } & \text { URL: http://dx.doi.org/10.5539/ijms.v6n3p87 }\end{array}$

\begin{abstract}
Fashion is a major part of online consumer culture. In addition to shopping, consumers engage in diverse practices related to fashion consumption. The purpose of this paper is to identify and analyze consumers' online fashion consumption practices. The study uses a practice-theoretical framework. The empirical material consists of two focus group interviews with thirteen informants and observations of fashion websites. Four interlinked online fashion consumption practices were identified: dreaming, expertise, information search and being part of a community. In addition, twelve procedures related to these practices were identified. The findings indicate that fashion website content should be able to support consumers' online fashion consumption practices to enable and enhance value creation, facilitate purchase and support the consumption of fashion items. Consumers online fashion consumption practices play a key role in engaging consumers on the website and in directing them toward a purchase.
\end{abstract}

Keywords: internet, online, consumer behavior, fashion websites, focus groups, practice theory

\section{Introduction}

Consumption is increasingly taking place online. Not only are online transactions in web stores acquiring considerable momentum, but consumers also allocate an increasing amount of time to other online activities. Consumers read product reviews, follow blogs and join online communities, sharing their views and opinions with others (Kozinets, Hemetsberger, \& Schau, 2008; Kozinets, De Valck, Wojnicki, \& Wilner, 2010; Kulmala, Mesiranta, \& Tuominen, 2012; Scaraboto \& Fischer, 2013; Närvänen, Kartastenpää, \& Kuusela, 2013). Hence, shopping is only one consumption practice among many others. Online environments, also in the context of fashion consumption, are becoming everyday life, a change which should encourage us to shift focus on the variety of consumer practices conducted online.

This article argues that more emphasis should be placed on understanding consumers' online fashion consumption practices. A practice can be defined as a "routinised type of behaviour which consists of several elements, interconnected to one another: forms of bodily activities, forms of mental activities, things and their use, a background knowledge in the form of understanding, know-how, states of emotion and motivational knowledge" (Reckwitz, 2002, p. 249). It has been suggested that engaging in shared consumption practices is how consumers actually create value and also innovate together (Schau, Muñiz, \& O'Guinn, 2009; Kozinets et al., 2008). However, engaging in diverse consumption practices may also lead to a purchase. That is why businesses in the fashion marketing and management sector should understand their customers' online practices more profoundly.

Generating understanding of online consumption is a topical issue for both scholars and practitioners of marketing. In the context of fashion marketing and management, in addition to exploring practices revolving around shopping, becoming aware of the diverse variety of practices related to consuming fashion online is critically important. It is a necessity when deepening the understanding of fashion, building competitive advantage in the online environment and providing managerial implications for practitioners. It helps companies personalize and increase the relevance of their websites, design their online presence as well as to breach the gap between their website design and consumers' desires (Siddiqui, O’Malley, McColl, \& Birtwistle, 2003). To address these issues, the purpose of this research is to identify and analyze consumers' online fashion consumption practices. 
First we briefly review the relevant literature on online environments and practice theory. Then we discuss the data including focus group interviews and observations of fashion-related websites and the data analysis conducted using a practice-theoretical framework that has lately been increasingly used in studies of consumption (Warde, 2005; Schau et al., 2009; Magaudda, 2011; Alakärppä \& Valtonen, 2011; Närvänen, Saarijärvi, \& Simanainen, 2013). The findings section addresses the online practices identified as relating to fashion consumption. Discussion and conclusions sections may be found at the end of the study.

\section{Literature Review}

\subsection{The Online Environment}

In the context of fashion consumption, online shopping has become an important topic for research. Incorporating interactivity and offering both utilitarian and hedonic benefits for the online fashion consumer have been noted to be important strategies (McCormick \& Livett, 2012). In a recent model of the behavior of the e-consumer, themes such as consumers' beliefs, attitudes, and intentions toward online shopping and online stores, as well as store image, atmospherics, and consumer traits and emotional factors were considered (Dennis, Merrilees, Jayawardhena, \& Wright, 2009). Yet shopping forms only a small part of the consumer's overall online consumption practices. Similarly with print media, movies, videos, or even food retailing, online fashion consumption is a wider phenomenon that has many elements, including the virtual and material, commercial, and noncommercial (Magaudda, 2011). The rise of social media and fashion-related consumer blogs provide evidence for this evolution (Kulmala et al., 2012). Hence, an extended view of the variety of activities consumers actually carry out online is merited.

The virtual environment is described as information rich, immaterial, and constantly changing (Denegri-Knott \& Molesworth, 2010b). These characteristics may help consumers compensate for their inability to fulfill their material desires (Denegri-Knott \&Molesworth, 2010a). The different forums and virtual spaces such as websites, virtual worlds and games can also create new practices and opportunities for consumption. Denegri-Knott and Molesworth (2010a) term these practices Digital Virtual Consumption (DVG). It is not merely imaginary, but experienced in a virtual space. However, the objects cannot be used in the material reality and consumers have fewer sensory stimuli available to them. According to Kozinets (2002, p. 61), the term online is preferable to the term virtual, because these practices are no less real than physical practices. The virtual or online space is not a substitute for, but an extension of, material reality. Instead of perceiving the internet as a medium, it should be considered as a space where consumers spend time, communicate and do things (Burbules, 2004). Not all virtual spaces are consumption oriented, but many support consumption practices. For instance, consumers may browse and window-shop with less effort than in the material reality.

Despite the digitalization of contemporary consumption, the study of online practices has remained underexplored, although some pioneering work has been published. To a large extent, these studies have focused on online communities, for example, from the perspective of value-creating practices (Schau et al., 2009) or innovation practices (Füller, Jawecki, \& Mühlbacher, 2007; Kozinets et al., 2008). An increasing proportion of the practices related to fashion consumption has moved online. Thus, the practice-theoretical viewpoint can help grasp the manifold ways in which consumers consume fashion through websites, blogs, and online communities.

\subsection{Practice Theory}

Practice theory has come to be utilized in marketing and consumer research mostly within the larger framework of Consumer Culture Theory (Arnould \& Thompson, 2005). It is a school of thought that focuses on the dynamics between consumers, markets and cultural meanings, connecting the individual to a broader social context. Consumer Culture Theory focuses not only on the purchase phase of consumption, but takes into account the contextual, experiential and symbolic aspects of the whole consumption cycle, for instance regarding the way consumption is used to construct identity or as a reason to join consumption collectives. In relation to fashion, CCT researchers have revealed how consumers express themselves and negotiate the prevailing sociocultural discourses available to them (Thompson \& Haytko, 1997; Murray, 2002). Practice theory thus follows in this tradition of explaining and understanding consumption as symbolic action (Reckwitz, 2002; Gabrielli, Bachi, \& Codeluppi, 2013; Boulaire \& Cova, 2013).

Practice theory defines practices as routine ways of doing things, moving objects, relating to objects, and describing and understanding the world (Reckwitz, 2002, p. 250; Shove \& Pantzar, 2005, p. 44). A practice contains several elements that are interconnected, such as bodily movements, mental activities, things and their use, know-how, emotions and motivational knowledge (Reckwitz, 2002, p. 249). Practice theory sees the world as consisting of practices that individual people (practitioners) carry and perform. Practices are coordinated entities, but they require active carriers to sustain them (Warde, 2005, p. 134; Shove \& Panzar, 2005, p. 49). 
Individual consumers thus become unique entities where different practices intersect. The elements of a single practice depend on where it is enacted and by whom. In a structured way, practices create value by making activities repeatable patterns (Schau et al., 2009). When the consumer successfully enacts a practice and produces value, it is likely that they will also expand their repertoire of practices (van Doorn et al., 2010). Practices also always contain a seed of change, because their elements may be varied and individual consumers enact them differently (Warde, 2005; Shove \& Pantzar, 2005).

According to practice theory, practices are processes of integration, the elements of which are commonly called understandings, procedures and engagements (Schatzki, 1996; Warde, 2005; Schau et al., 2009). The fourth element that is sometimes neglected but always implicitly part of practice-theoretical accounts is that of objects.

First, understandings are shared knowledge regarding the way a practice is enacted, consisting of information, know-how and understanding of norms and rules as well as cultural meanings (Reckwitz, 2002). The second element of a practice is that of procedure. It consists of specific "doings and sayings" guided by the prior element of understanding. Schau et al. $(2009$, p. 34) identify several procedures related to brand use such as improving and customizing the product. In a virtual context, procedures are less observable than physical actions, because they consist of writing messages and posting pictures, for instance. Engagement provides the third element of a practice. It consists of emotions and motivational knowledge, goals and moods that give the action meaning and tie it to a certain context. Although practices are routinized activities, they always entail some purpose. For instance in the context of fashion, the understanding of how to dress in a certain style and according to certain norms, the specific procedures related to dressing in that way as well as the desires and goals such as pursuit of a certain identity are interconnected and influence how the practice is enacted. Often participating in a practice also creates new desires (Warde, 2005; Schau et al., 2009). Finally, objects are material elements related to practices. They help the consumer enact the practice and, for instance, to be classified as part of a certain group or outside of it (Holt, 1995). New practices inspire needs for new objects to complement them. Next, we explain how the study was conducted in detail.

\section{Methodology}

\subsection{Data Generation}

The main data generation method for the study was focus group interviews. The aim was to achieve an understanding of what consumers do on fashion-related websites and why. Focus group interviews are situated in between a structured interview and participant observation. They encourage different perspectives and opinions on the subject matter. The aim was to create a relaxed atmosphere in which to conduct an informal discussion. The researchers called on their personal contacts to select the first group of interviewees, and then applied a snowballing technique to find more participants. An enthusiasm for fashion were used as a selection criterion. Two focus groups were assembled in the spring of 2011; one with six members, the other with seven. The focus group participants knew each other beforehand, which made the discussion open and rich. Some participants worked in fashion retailing as part-time salespeople and some of them had a fashion blog. None of them had a fashion-oriented education. A detailed list of the participants is presented in Table 1.

Table 1. Focus group informants

\begin{tabular}{llll}
\hline Focus group & Name & Gender & Age \\
\hline 1 & Mari & Female & 23 \\
1 & Laura & Female & 21 \\
1 & Jaana & Female & 23 \\
1 & Jenna & Female & 26 \\
1 & Sanna & Female & 24 \\
1 & Tiia & Female & 22 \\
2 & Toni & Male & 24 \\
2 & Veronika & Female & 25 \\
2 & Hanna & Female & 25 \\
2 & Minna & Female & 27 \\
2 & Marika & Female & 23 \\
2 & Leena & Female & 28 \\
2 & Anna & Female & 26 \\
\hline
\end{tabular}


The sizes of the focus groups were deliberately restricted to ensure that each participant's opinions would be heard. The participants' age ranged from 21 to 28 years old and there were twelve women and one man. The focus groups were given instructions to talk about the subject as broadly as possible and encouraged to express any opinions and perceptions that they had. A researcher acted as facilitator, giving the participants only the broad topics to be discussed. The duration of the interviews was 55 minutes and 1 hour 45 minutes respectively and they were recorded and transcribed for analysis (Figure 1).

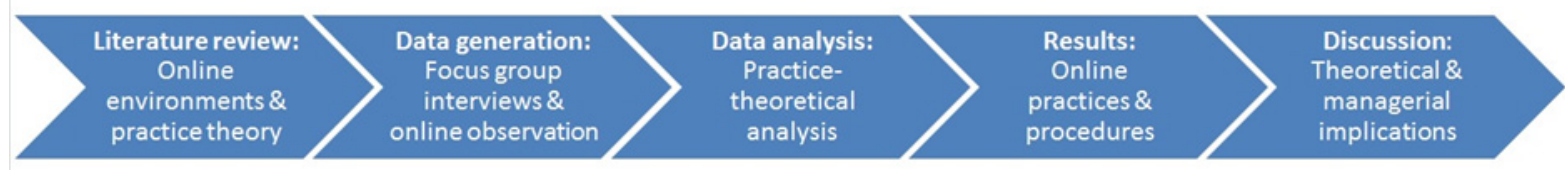

Figure 1. The research process

The information gained from the focus groups was then supported by observing the fashion websites that were mentioned by the focus group participants. The combination of these methods enabled us to explore the nuances of consumption practices, which is considered as important in practice theoretical inquiry (Boulaire \& Cova, 2013). Because the consumption practices took place in the online environment, observing the websites complemented focus groups which concentrated more on how consumers themselves reflected upon their practices. Observing websites included bringing forth the content and consumer interactions related to the ways in which consumption practices were materialized online. All of the websites mentioned in the focus groups were first listed and then those that were most often mentioned and which had the most active content were selected. The websites were observed in June and July 2011, enabling the collating of 5120 comments. They were read selectively and grouped at the data generation phase. The comments broadly mirrored the issues raised in the focus group discussions.

\subsection{Data Analysis}

The data analysis was based on practice theory and standard qualitative research procedures (e.g., Spiggle, 1994). It started by reading carefully the transcribed focus group data and identifying the central phrases and key words. Each phrase was then labeled with one or more meanings that were considered to best characterize it. This made it possible to organize the data in a meaningful way. In the next phase, the phrases were grouped together into themes that became identified as 12 procedures that consumers enact online. Next, similar themes were connected and four practices emerged as a result. These practices were then analyzed through focusing on the understandings and emotional engagements involved in them. At the final stage, the analysis moved back from the broad level of practices to ensure that the identified procedures were correctly grouped and that the practices were accurately described and labeled. The website observation data was grouped alongside the focus group data throughout the analysis process with the objective to support and deepen the findings and their interpretation.

\section{Findings}

The data analysis identified four practices that encapsulate procedures, understandings and emotional engagements. The four practices were dreaming, expertise, information search, and being part of a community. As Reckwitz argued (2002), practices are often interconnected, which was also the case with these four examples. However, they can be discussed separately and as a whole, and they manage to capture the central characteristics of online fashion consumption practices. These practices are discussed in more detail below.

\subsection{Dreaming}

The practice of dreaming was central to how consumers constructed their identity and communicated it to others (Schau \& Gilly, 2003; see also Jiang \& Cova, 2012). The consumers engaged in both fantasizing about lifestyles and things that they considered accessible as well as those they considered out of their reach, at least for the foreseeable future. Procedures related to dreaming included browsing images where the underlying emotional engagements were related to relaxation, aesthetic pleasure and becoming inspired.

Many hours may pass and I don't even notice it when I'm browsing online fashion sites, looking at the images and reviews. - Anna

Besides finding information through browsing the images, the consumers felt that they were transported into a dream world. Thus, images were considered far more important than the text that served only to support the 
visual content. Finding a good source of images when browsing new websites generated enthusiasm. Consumers also engaged in the procedure of imitating, where they collected images and stored them to their computer in order to experiment and plan how they could incorporate ideas into their own style.

I have a couple of celebrities whose styles I like very much, so I sometimes just google their photos and look for ideas. -Toni

The underlying understandings related to imitating included the need to modify or adapt the ideas in different ways in order to show individuality. Consumers did not want to directly copy what they saw, because that was considered to demonstrate a lack of taste or personality. Enabled by the web environment, it was easy to play with the styles, which was considered as a safe, entertaining and informative way to find out whether it was something that the consumer wanted to implement through purchase. The web environment also offers helpful guidance for purchasing, such as through hyperlinks and communities. Fashion bloggers represent a source of information for their audience through presenting their unique personal style by sharing "outfits of the day" or spotting trends (Kulmala et al., 2012). However, if the consumer could not imitate the style (e.g., due to some elements of an outfit being unavailable), they would also become frustrated:

It is frustrating, if there are some products that people praise and then you cannot order them for delivery to Finland. But then I just try to find something similar. - Laura

The emotional engagements related to imitating included the need to play and experiment, which also reinforced the perceived expertise of the consumer and their connection with those consumers with a higher status in the online communities and blogs. The third procedure related to dreaming was fantasizing about becoming a professional. In the context of our data, this meant that consumers aspired to products and other resources related to being a professional in the fashion industry or in the online fashion world. This was often realized through more active participation in commenting on the blogs or showing one's own expertise.

My dream profession would be a fashion blogger. Like [when] you could actually have the time to do it properly and even get paid for it. I cannot imagine anything better than that. - Marika

Thus, the consumers engaged in competing for status through acquiring resources and investing them in developing their skills, competences and tools.

\subsection{Expertise}

The practice of expertise refers to extensive know-how, the understanding of a sense of style, the use of appropriate products and how to maintain them. Engaging in this practice reinforced the consumers' sense of being superior to the average consumer in relation to their expertise on fashion. Procedures included upgrading status and self-worth enacted through purchasing and owning appropriate products, which was readily reported in the websites observed. Consumers also reported that they felt proud just knowing that they owned the products that were praised by the bloggers they admired. Our findings also support earlier research on how consumers show their status through recommending products and uses to other consumers on online forums (Schau \& Gilly, 2003; Schau et al., 2009).

You notice that you are better informed than the average consumer when occasionally you encounter some "new" tips or products that you have already known about for a long time. -Veronika

Consumers also enjoy testing their expertise playfully, such as by participating in contests and tasks where they have to establish their sense of style and get feedback on it.

Another procedure related to expertise is that of familiarity with information sources. As argued by Kozinets et al. (2008, p. 349), online communities of interest represent a rich information source for any topic. In our data, consumers engaged in showing their expertise through being familiar with the most popular bloggers and visiting the websites that were considered best. Being selective and learning to distil good information from bad then became one of the key competences for consumers. This competence was also gradually developed over time as people engaged to a greater extent in consuming fashion online:

Compared to what I knew a couple of years ago, I have managed to improve my sources of information. And it is part of the whole feeling that you know the top sites that are not familiar to just anybody. - Toni

In another study about online communities devoted to environmentally-friendly fashion, it was noted that the consumers' experience and competence developed over time and that could be seen in the nature of their discussions (Cervellon \& Wernefelt, 2012). Our findings hence provide support for the notion that consumers' online fashion consumption is a long-term pursuit of appropriate knowledge and competence. It is not just something they do occasionally and with no sense of purpose. 
The third procedure related to expertise is that of fashion do-it-yourself (DIY) projects. Consumers were most grateful for website content that offered concrete step-by-step guidelines, such as those on dressing or make-up. In the background of DIY projects there was the understanding that general fashion know-how can somehow be adapted to achieving personal goals and skills (see also Gabrielli et al., 2012). Consumers would also return to sites that they found helpful. Consumers were also interested in ways to circulate, modify and extend the use of their products.

Similar to the practice of dreaming, the practice of expertise was also characterized by aspirations to become more professional in ways that included using more advanced materials, techniques or tools. The web environment supported this practice because consumers could find actual professionals sharing their tips and product recommendations. The sense of being a professional was also enhanced through opportunities to participate in creating new website content or being a member of a user panel.

I have participated in a couple of user panels and even though I know that I'm not the only participant, it is still nice to receive the emails for panel members. You feel that you are actually part of a fashion website's designer team. - Laura

For consumers, responding to website designers' questions did not require a lot of resources and some of them would have been interested in participating more actively.

\subsection{Information Search}

The practice of information search is not surprising, considering the dominant role of the Internet as an information source today. However, our findings illustrate the systematic and profound nature of the information search undertaken by consumers. Fashion products may easily be associated with consumers' spontaneous purchasing behavior, but our informants' purchasing process was often preceded by a long process of dreaming and information search.

Nowadays when I see a commercial or hear about a product, I will first go and google for reviews on forums and blogs and see video reviews on Youtube. -Mari

The consumers reported that they would only very rarely buy products that they had never heard of. Searching for information has been argued to represent imagined consumption in a virtual space (Denegri-Knott \& Molesworth, 2010). However, the more deliberative nature of the purchasing does not necessarily translate into fewer purchases, and may even mean more commitment and loyalty.

Procedures related to this practice included recommending, which consisted both of reading reviews and writing them. It was clearly evident that consumers seek information more from their peers via blogs, YouTube or social media, than they do from companies' websites. The reasons for this were not only the perceived trustworthiness of information, but also the perceived scarcity of information on company websites compared to other sources. Company websites also often lack an important aspect of information: a comparison of different products. The availability of information, images, the usability of the website, and getting the purchasing information from the same site was often the most effective factor. Another procedure related to information search is looking for tips for use (see also Kulmala et al., 2012). Thus, the search for information does not end at the point-of-purchase but instead consumers try to foster their sense of satisfaction and value throughout the consumption cycle. Prolonging the duration of the product was also related to this aspect (Schau et al., 2009).

I have one palette of eye shadow that is my favorite and it has ten different colors, but at the beginning I noticed I was using only four colors and always in the same way. But then I looked for tips online and guidance for doing make-up, so I got a lot of new ideas. - Hanna

Finally, another procedure related to information search was that of product reviews. Consumers would automatically look for product reviews relating to products that interested them. This was a highly routinized procedure that was grounded in an understanding of the lack of trust in advertising and the desire to avoid unwise purchases. Many websites encourage consumers to write post-purchase reviews by offering discounts or other benefits against further purchases. Füller et al. (2007) noted that writing product reviews is another important part of innovation.

\subsection{Being Part of a Community}

The practice of being part of a community entailed developing the emotional engagement to become part of the group. Magaudda (2011) found a desire to create more personal relationships with artists in a study conducted within a community of music lovers. Our findings provide a complementary view on this. Consumers thought that the information was more reliable and the practices were considered better the better they knew the 
information source. The consumers were interested not only in fashion, but also in the personal lives of popular influencers. In other words, they formed parasocial relationships with them.

I feel as though they were my best friends, even though they do not even know me. -Hanna

This finding may provide support for the argument that it is easier for consumers to relate to people rather than faceless company websites. In addition, the procedure of creating companionship was apparent in our data. Consumers find it liberating and fun to be with people who understand their enthusiasm and share their feelings about fashion (Cervellon \& Wernefelt 2012). The online world offers a community of like-minded others with whom consumers can share practices and thoughts (Holt, 1995).

It is so nice to read and look at others' views, when they are similarly enthusiastic about it, so you will not be ashamed or feel superficial. - Anna

For me it is like a second group of friends, because very few of my real friends are as up to date and informed about these issues, so it is nice to ask and read others' comments online. - Toni

Toni's comment illustrates that consumers do not feel that the online world provides them with "real friendships", because interaction is restricted to the area of interest.

Table 2. Online fashion consumption practices and procedures

\begin{tabular}{ll}
\hline Practice & Procedures \\
\hline Dreaming & - Browsing images \\
Building identity and a desirable lifestyle & - Imitating \\
& - Fantasizing about becoming a professional \\
\hline Expertise & - Upgrading status and self-worth \\
$\begin{array}{l}\text { Developing a feeling of expertise through appropriate } \\
\text { knowledge and competence. }\end{array}$ & - Familiarity with information sources \\
& - DIY projects \\
\hline Information search & - Aspiring to be more professional \\
\hline Looking for and generating the most reliable information available & - Recommending \\
& - Looking for usage tips \\
\hline Being part of a community & - Product reviews \\
Achieving a sense of belonging to a community & - Getting to know the information source personally \\
\hline
\end{tabular}

\section{Discussion}

The purpose of this study was to identify and analyze consumers' online fashion consumption practices. Thus, the focus was moved from shopping toward the diversity of consumption practices conducted online. A data set was generated through a combination of focus group interviews and website analysis. As the focus of the study was on consumers' online practices, a framework from practice theory was employed resulting in the identification of four practices. These were dreaming, expertise, information search, and being part of a community. These practices were further divided into 12 procedures.

The findings contribute first by building a practice-theoretical perspective on online fashion consumption. Using practice theory enables a truly consumer-centric view of how fashion is consumed online and what meanings consumers ascribe to their acts of consumption. Second, the study underlines the importance of focusing on the online practices of individual consumers, because previous research has focused mainly on collective practices in online communities. It is important to note that our findings also illustrate that online fashion consumption should not be considered merely the hedonistic pursuit of entertainment, as it can in fact be an intensive, rewarding and time-consuming part of building an identity. Thirdly, consumption is increasingly taking place within the online environment. Consequently, it is important to understand that online practices also perform an increasingly important function in fashion consumption. Our findings thus shift attention from mere online shopping transactions to more diverse online consumption practices.

\section{Managerial Implications}

As companies in the fashion industry increasingly extend their presence from the offline to the online environment, they come under pressure to renew their competitive advantage. Companies must build competitive online strategies and choose whether to concentrate on low price, wide product variety, service, or rapid delivery. Moreover, fostering interaction and dialogue with customers is a general demand in today's competitive 
landscape. In these efforts, it is of utmost importance to understand the practices of consumers as they consume fashion online.

Table 3 presents the key managerial implications of the findings of this study. The four identified practices uncover how consumers consume fashion online and thus will help firms design attractive online environments that facilitate that consumption. For example, understanding the role of dreaming would help firms provide customers with an opportunity to co-create and experiment with various fashion styles, and fashion firms might invite customers to send their own sketches or designs to be rated by their peers or experts. Since fashion bloggers are seen as opinion leaders, companies might for instance invite them to discuss fashion-related topics on their websites. As a result, companies are able to redefine their role as providers of fashion goods to supporting consumers' fashion-related practices.

Table 3. Suggestions for managers

\begin{tabular}{|c|c|}
\hline Practice & Suggestions for managers \\
\hline \multirow[t]{5}{*}{ Dreaming } & - Provide customers with a multitude of images illustrating different styles and trends \\
\hline & - Provide customers with the opportunity to co-create and experiment with various fashion \\
\hline & styles as part of the decision-making process \\
\hline & - Invite consumers to send their own sketches or designs for others to rate \\
\hline & - Use a number of photos as an important element of the fashion-related online environment \\
\hline \multirow[t]{4}{*}{ Expertise } & - Offer both basic and advanced fashion guidelines to support consumers' identity building \\
\hline & - Discuss and analyze contemporary fashion styles \\
\hline & - Compare different styles of celebrities, for example \\
\hline & - Invite consumers to send their own sketches or designs for others to rate \\
\hline \multirow[t]{2}{*}{ Information search } & $\begin{array}{l}\text { - Provide consumers a convenient access to relevant fashion-related information by } \\
\text { summarizing relevant information sources }\end{array}$ \\
\hline & $\begin{array}{l}\text { - Create a consumer-led community that helps other consumers in varying issues related to } \\
\text { fashion }\end{array}$ \\
\hline \multirow[t]{4}{*}{ Being part of a community } & $\begin{array}{l}\text { - Create an online environment that can be used as a platform to discuss and share } \\
\text { experiences with other consumers and friends }\end{array}$ \\
\hline & - Invite bloggers to discuss fashion-related topics \\
\hline & - Engage through social media \\
\hline & - Instigate competitions among the members of the community \\
\hline
\end{tabular}

\section{Conclusion}

The main objective of the study was not to provide generalizable results, but to conduct a practice-theoretical inquiry to uncover the practices through which fashion consumption takes place online. However, given the limited set of data, caution should be applied when applying the findings. It is also important to note that due to the context of online fashion consumption, the informants were mainly young women. Although online fashion consumption is heavily asymmetric in terms of age groups and gender, exploring this phenomenon among varying consumer groups could enrich the study findings, and also serve as an interesting future research topic. Furthermore, measuring how these practices are linked with important marketing measures such as customer satisfaction or repurchase intentions would further enhance understanding of online fashion consumption.

\section{References}

Alakärppä, I., \& Valtonen, A. (2011). Practice-based perspective on technology acceptance: Analyzing bioactive point of care testing. International Journal of Marketing Studies, 3(3), 13-29. http://dx.doi.org/10.5539/ijms.v3n3p13

Arnould, E. J., \& Thompson, C. J. (2005). Consumer culture theory (CCT): Twenty years of research. Journal of Consumer Research, 31, 868-882. http://dx.doi.org/10.1086/426626.

Boulaire, C., \& Cova, B. (2013). The dynamics and trajectory of creative consumption practices as revealed by the postmodern game of Geocaching. Consumption, Markets \& Culture, 16(1), 1-24. http://dx.doi.org/10.1080/10253866.2012.659434.

Burbules, N. (2004). Rethinking the virtual. E-Learning and Digital Media, 1(2), 162-183. http://dx.doi.org/10.2304/elea.2004.1.2.2 
Cervellon, M. C., \& Wernerfelt, A. S. (2012). Knowledge sharing among green fashion communities online: Lessons for the sustainable supply chain. Journal of Fashion Marketing and Management, 16, 176-192. http://dx.doi.org/10.1108/13612021211222860

Denegri-Knott, J., \& Molesworth, M. (2010a). Concepts and practices of digital virtual consumption. Consumption Markets \& Culture, 13, 109-132. http://dx.doi.org/10.1080/10253860903562130

Denegri-Knott, J., \& Molesworth, M. (2010b). Love it. buy it. sell it: Consumer desire and the social drama on eBay. Journal of Consumer Culture, 10, 56-79. http://dx.doi.org/10.1177/1469540509355025

Dennis, C., Merrilees, B., Jayawardhena, C., \& Wright, L. T. (2009). E-consumer behavior. European Journal of Marketing, 43, 1121-1139. http://dx.doi.org/10.1108/03090560910976393

Füller, J., Jawecki, G., \& Mühlbacher, H. (2007). Innovation creation by online basketball communities. Journal of Business Research, 60, 60-71. http://dx.doi.org/10.1016/j.jbusres.2006.09.019

Gabrielli, V., Baghi, I., \& Codeluppi, V. (2013). Consumption practices of fast fashion products: A consumer-based approach. Journal of Fashion Marketing and Management, 17, 206-224. http://dx.doi.org/10.1108/JFMM-10-2011-0076

Holt, D. B. (1995). How consumers consume: A typology of consumption practices. Journal of Consumer Research, 22, 1-16.

Jiang, L., \& Cova, V. (2012). Love for luxury, preference for counterfeits - A qualitative study in counterfeit luxury consumption in China. International Journal of Marketing Studies, 4(6), 1-9. http://dx.doi.org/10.5539/ijms.v4n6p1

Kozinets, R. (2002). The field behind the screen: Using netnography for marketing research in online communities. Journal of Marketing Research, 39, 61-72. http://dx.doi.org/10.1509/jmkr.39.1.61.18935

Kozinets, R. V., De Valck, K., Wojnicki, A. C., \& Wilner, S. J. (2010). Networked narratives: Understanding word-of-mouth marketing in online communities. Journal of Marketing, 74(2), 71-89. http://dx.doi.org/10.1509/jmkg.74.2.71

Kozinets, R., Hemetsberger, A., \& Schau H. (2008). The wisdom of consumer crowds: Collective innovation in the age of networked marketing. Journal of Macromarketing, 28, 339-354. http://dx.doi.org/10.1177/0276146708325382

Kulmala, M., Mesiranta, N., \& Tuominen, P. (2013). Organic and amplified eWOM in consumer fashion blogs. Journal of Fashion Marketing and Management, 17, 20-37. http://dx.doi.org/10.1108/13612021311305119

Magaudda, P. (2011). When materiality "bites back": Digital music consumption practices in the age of dematerialization. Journal of Consumer Culture, 11, 15-36. http://dx.doi.org/10.1177/1469540510390499

McCormick, H., \& Livett, C. (2012). Analysing the influence of the presentation of fashion garments on young consumers' online behavior. Journal of Fashion Marketing and Management, 16, 21-41. http://dx.doi.org/10.1108/13612021211203014

Murray, J. B. (2002). The politics of consumption: A re-inquiry on Thompson and Haytko's (1997) 'Speaking of Fashion'. Journal of Consumer Research, 29, 427-440. http://dx.doi.org/10.1086/344424

Närvänen, E., Kartastenpää, E., \& Kuusela, H. (2013). Online lifestyle consumption community dynamics: A practice-based analysis. Journal of Consumer Behaviour, 12(5), 358-369. http://dx.doi.org/10.1002/cb.1433/pdf

Närvänen, E., Saarijärvi, H., \& Simanainen, O. (2013). Understanding consumers' online conversation practices in the context of convenience food. International Journal of Consumer Studies, 37, 569-576. http://dx.doi.org/10.1111/ijcs.12021/pdf

Reckwitz, A. (2002). Toward a theory of social practices. European Journal of Social Theory, 5, 243-263. http://dx.doi.org/10.1177/13684310222225432

Scaraboto, D., \& Fischer, E. (2013). Frustrated fatshionistas: An institutional theory perspective on consumer quests for greater choice in mainstream markets. Journal of Consumer Research, 39, 1234-1257. http://www.jstor.org/stable/10.1086/668298

Schatzki, T. (1996). Social practices: A Wittgensteinian approach to human activity and the social. Cambridge: Cambridge University Press.

Schau, H. J., \& Gilly, M. (2003). We are what we post? Self-presentation in personal web space. Journal of 
Consumer Research, 30, 385-404. http://dx.doi.org/10.1086/378616

Schau, H., Muniz, A., \& Arnould, E. (2009). How brand community practices create value. Journal of Marketing, 73(3), 30-51. http://dx.doi.org/10.1509/jmkg.73.5.30

Shove, E., \& Pantzar, M. (2005). Consumers, producers and practices: Understanding the invention and reinvention of Nordic walking. Journal of Consumer Culture, 5, 43-64. http://dx.doi.org/10.1177/1469540505049846

Siddiqui, N., O’Malley, A., McColl, J. C., \& Birtwistle, G. (2003). Retailer and consumer perceptions of online fashion retailers: Web site design issues. Journal of Fashion Marketing and Management, 7, 345-355. http://dx.doi.org/10.1108/13612020310496949

Spiggle, S. (1994). Analysis and interpretation of qualitative data in consumer research. Journal of Consumer Research, 21, 491-503. http://dx.doi.org/2489688

Thompson, C., \& Haytko, D. L. (1997). Speaking of fashion: Consumers' uses of fashion discourses and the appropriation of countervailing cultural meaning. Journal of Consumer Research, 24, 15-42. http://dx.doi.org/10.1086/209491

Van Doorn, J., Lemon, K., Mittal, V., Nass, S., Pick, D., Pirner, P., \& Verhoef, P. (2010). Customer engagement behavior: Theoretical foundations and research directions. Journal of Service Research, 13, 253-266. http://dx.doi.org/10.1177/1094670510375599

Warde, A. (2005). Consumption and theories of practice. Journal of Consumer Culture, 5, 131-153. http://dx.doi.org /10.1177/1469540505053090

\section{Copyrights}

Copyright for this article is retained by the author(s), with first publication rights granted to the journal.

This is an open-access article distributed under the terms and conditions of the Creative Commons Attribution license (http://creativecommons.org/licenses/by/3.0/). 